\title{
GRUPOS ETNICOS ITALIANOS, RELIGIOSIDADE E NEGOCIAÇÃO DE IDENTIDADES NA REGIÃO CENTRAL DO RIO GRANDE DO SUL
}

\author{
ITALIAN ETHNIC GROUP, RELIGION AND NEGOTIATING IDENTITIES IN \\ THE CENTRAL REGION OF THE RIO GRANDE DO SUL
}

\author{
Cesar Augusto Barichello ${ }^{1}$ e Julio Ricardo Quevedo dos Santos ${ }^{2}$
}

Recebido em: 07/04/2012 Aprovado em: 09/05/2012

\begin{abstract}
RESUMO
O objetivo deste artigo é discutir a relação que se estabelece entre os grupos étnicos italianos, a religiosidade e a negociação de identidades na Quarta Colônia de Imigração Italiana, particularmente no atual município de Silveira Martins, Rio Grande do Sul. Com esse intento, o texto está subdividido em três partes: a primeira aborda as noções de grupo étnico, raça e nação; a segunda, a negociação da identidade do imigrante pelos grupos étnicos italianos; e a terceira aborda o papel da religiosidade na negociação da identidade do imigrante, destacando o contexto da Igreja Católica no Brasil e no Rio Grande do Sul do século XIX.

Palavras-chave: Etnias italianas; Religiosidade; Negociação de identidades.
\end{abstract}

1 Introdução: em torno das noções de grupo étnico, raça e nação

Fenton (2003) procura diferenciar as noções de grupo étnico (etnia), raça e nação, destacando que: "Etnia tem um significado próximo ao de nação, mas carece do sentido de entidade autogovernativa, se um grupo étnico quiser governar a si próprio precisa se auto reconhecer com uma nação" (FENTON, 2003, p. 70). Segundo o autor, existe uma parte comum entre essas noções - com algumas diferenças marcantes na periferia. A ideia de descendência ou ancestralidade é o núcleo comum, e,

\begin{abstract}
The goal of this article is to discuss the relationship that is established between the Italian ethnic groups, religiosity and identity negotiation in the fourth colony of Italian immigration, particularly in the present-day municipality of Silveira Martins, Rio Grande do Sul, Brazil. With this intent text is subdivided into three parts: the first discusses the notions of ethnic group, race and nation; the second, the negotiation of immigrant identity by Italian ethnic groups; and the third discusses the role of religiosity in the negotiation of immigrant identity in the context of the Catholic Church in Brazil and Rio Grande do Sul, in the 19th century.
\end{abstract}

Keywords: Italian ethnicity; Religion; Identity negotiation.

implicada nos três conceitos, encontramos a noção de cultura. Ressalta, ainda, que existem referências partilhadas nas noções de étnico, raça e nação, pois raça e nação partilham uma origem comum; enquanto étnico refere-se tanto à raça quanto à nação.

Tanto sob o ponto de vista etimológico como histórico, as utilizações dos termos, "étnico", "nação" e "raça" sugerem que os três têm uma base em comum. Em seus usos, passados e presentes, estão ideias de descendência comum, de crença comum em uma descendência partilhada e sua referência a um local, país, reino ou outra forma

${ }^{1}$ Mestre em Patrimônio Cultural pela Universidade Federal de Santa Maria, Brasil. Fundador e primeiro presidente da Associação Italiana de Santa Maria (1985-1992), secretário da Cultura e Turismo do município de Silveira Martins-RS (2005-2008) e secretário adjunto da Cultura do município de Santa Maria-RS (2009-2012). Telefone: (55) 96234489. E-mail: cesarebarichello@gmail.com.

${ }^{2}$ Doutor em História Social pela Universidade de São Paulo, Brasil. Professor associado II da Universidade Federal de Santa Maria. Docente dos Programas de Pós-Graduação: Mestrado Profissionalizante em Patrimônio Cultural e Mestrado Acadêmico em História, ambos pela UFSM. Telefone: (55) 96043939. E-mail: j_quevedo@uol.com.br. 
de Estado. "Estreitamente associadas ou implicadas nestes termos - e especialmente em ethnos e étnico - estão as noções de carácter cultural, língua, e de diferença e exclusão" (FENTON, 2003, p. 31). Fenton (2003) ainda alerta para o fato de que cultura e etnicidade não são a mesma coisa, pois as culturas são simultaneamente mais amplas e mais restritas do que, por exemplo, as nações, já que as nações podem ser divididas e diferenciadas por classe e culturas regionais e diferenças de língua e religião.

Raça refere-se a comunidades de descendência e cultura com dois aditamentos específicos: 1) A idéia de que os grupos locais são casos de divisões do gênero humano abstractamente concebidas; 2) A idéia de que a raça faz referência específica à diferença física ou visível com marcador principal da diferença e desigualdade. Nação refere-se a comunidades de descendência e cultura com um aditamento especifico: a assunção de que as nações estão ou devem estar associadas a um Estado ou forma política equivalente. Grupo étnico refere-se a comunidades de descendência e cultura com três aditamentos específicos: 1) O grupo é uma espécie de subconjunto no quadro de um Estado-nação; 2) $\mathrm{O}$ ponto de referência da diferença é tipicamente a cultura e não aparência física; frequentemente o grupo referido é 'outro' (estrangeiro, exótico, minoria) que não uma maioria presumida como não ‘étnica' (FENTON, 2003, p. 36).

A ideia central dos três termos é a ancestralidade ou descendência comum, além disso, os termos têm individualmente significados peculiares, como por exemplo, a palavra raça tem uma forte associação com a diferença biológica.

No início do século XX, a noção de raça estava largamente difundida, e a ideia de que a população mundial poderia ser classificada em raças era um pensamento aceito, como resultado das ideologias racistas do século XIX, utilizadas pelos intelectuais, governos e instituições na justificativa da expressão e dominação neocolonialista na África e Ásia. As primeiras críticas ao uso do conceito de raça foram feitas especialmente por parte do sociólogo francês Émile Durkheim e pelo antropólogo alemão Franz Boas, que procuraram substituir as explicações "raciais" por sociais e culturais, até que finalmente Huxley e Haddon propuseram formalmente a abolição do termo raça. As dificuldades nesse debate são acentuadas por duas questões primordiais: a questão de se os grupos são reais (ou socialmente construídos) e a questão de se as ligações do grupo são afetivas (orientadas pelo sentimento) ou instrumentais (FENTON, 2003).

Oro (1996) refere-se ao grande debate que opõe as duas principais visões acerca da identidade étnica: "primordialista" e "situacionista".

Para a ótica primordialista a identidade étnica constitui uma realidade inata, congênita, substancial, primordial, pois parte da definição de grupo étnico enquanto uma unidade cultural caracterizada por um certo número de traços objetivos, que são de ordem biológica, territorial, lingüística, econômica, cultural. [...] Para segunda perspectiva, a situacionista, a identidade étnica se caracteriza por um sentimento de pertencimento grupal baseado na auto-atribuição e atribuição pelos outros (ORO 1996, p. 612).

Barth (1976, p. 11), um dos representantes da perspectiva situacionista, define grupo étnico como "formas de organização social em população cujos membros se identificam e são identificados como tais pelos outros". Nessa perspectiva, a etnia é constantemente reconstruída, e, segundo Oliveira (1976), a análise, sob a ótica situacio- 
nista, não recai nas características culturais do grupo, mas no sistema interétnico, ou seja, no campo das relações entre os grupos sociais, que compõe o contexto gerador da identidade étnica enquanto identidade contrastiva.

A equiparação de "grupo étnico" à diferença cultural precisaria ser revista e poderia parecer senso comum dizer que os grupos étnicos são os "envelopes" que contêm a diferença cultural, porém a ênfase nas "fronteiras" do grupo, e não no conteúdo "cultural", inverte esse argumento, já que a ideia de diferença cultural mostraria uma tendência classificatória dos grupos étnicos (FENTON, 2003). O objeto de estudo do presente trabalho, por exemplo, trata de grupos étnicos que acreditavam em Deus e praticavam a religião Católica Apostólica Romana. Esse fato seria um fragmento do aporte cultural desses grupos e, ao mesmo tempo, o fator que permitiria a negociação da identidade regional com os grupos étnicos já radicados no território.

$\mathrm{O}$ conceito de fronteira de grupo indica um sentido relacional, ou seja, como um grupo se define e como define o outro e, ainda, como é traçada a fronteira entre eles. Sob esse ponto de vista, um elemento cultural, como a língua, o traje ou a religião, poderia funcionar como um delimitador de fronteira e também como elemento de negociação.

Para Bourdieu (1998), a atualização da história é derivada do habitus, o que faz entender as condições sociais de produção dos atores, bem como as condições institucionais, ou seja, a história objetivada e a incorporada. Os hábitos enraizados em práticas sociais são referidos pelo autor quando afirma que,

[...] qualquer ação histórica põe em presença dois estados da história ou do social: a história no seu estado objetivado, quer dizer a história que se acumulou ao longo do tempo nas coisas, máquinas, edifícios, monumentos, livros, teorias, costumes, direito, etc., e a história no seu estado incorporado, que e tornou habitus (BOURDIEU, 1998, p. 100).

Acreditamos que a repetição e incorporação de atos no cotidiano, a qual Bourdieu (1998) denomina habitus, pode ser relacionada à noção de etnicidade. Segundo Zanini (2006, p. 238),

[...] a etnicidade, enquanto uma forma de relação com o mundo e com as pessoas, produz categorias sociais pelas quais os descendentes orientam condutas, fazem opções, estabelecem vínculos sociais e afetivos, bem como constroem sua autoimagem (ZANINI, 2006, p. 238).

A persistência da etnicidade é um fenômeno recentemente reconhecido. O que não constitui uma falha das culturas antigas em mudar, mas a sua continuação em novas formas e novos contextos (FENTON, 2003). Essa continuidade está ligada a um processo permanente de negociação entre os que chegam e os que já habitam um determinado território, inserida em um contexto social, como procuraremos demonstrar a seguir.

Dessa forma, no plano do indivíduo, a identidade étnica se define simultaneamente pelo que é subjetivamente reivindicado e pelo que é socialmente atribuído (POUTIGNAT; STREIFFFENART, 1998).

\section{A negociação da identidade do imi- grante originário da península itálica na região central do Rio Grande do Sul}

A negociação da identidade do imigrante na região central do Rio Grande do Sul traz, em seu bojo, a questão da etnicidade. Apesar de termos uma percepção da identidade do imigrante como um bloco monolítico, essa identidade é multifacetada e formada por traços dos diferentes grupos éticos 
provenientes da península itálica.

Uma visão etimológica dos termos grupo étnico, raça e nação, demonstrada por Fenton (2003), auxilia no esclarecimento de que há uma essência considerável de significado partilhado, e que este se refere à ideia de "povo", de origens comuns, e aos conceitos de descendência e ancestralidade. Fenton (2003) argumenta que a etnicidade é sempre relacional e, dessa forma, ela pode também se referir àquelas pessoas com suas "origens" e "ancestralidade".

Para Fenton (2003, p. 23), as etnicidades são tanto "fundadas" quanto "construídas", pois "as identidades étnicas tomam forma em torno da experiência material partilhada real, do espaço social partilhado, das 'comunalidades' da socialização e das comunidades de língua e cultura". Simultaneamente, essas identidades possuem uma presença pública, pois elas são socialmente definidas numa série de declarações públicas, afirmações e imagens, tanto por membros de grupos étnicos quanto por não membros, e essas definições sociais fazem parte de uma construção e reconstrução contínua das identidades étnicas.

Segundo Lesser (2001, p. 18), a etnicidade "foi de importância critica para a negociação da identidade nacional brasileira nos últimos 150 anos". Ele defende que essa negociação ocorreu em todos os níveis da sociedade, e que o sentimento de serem diferentes e, mesmo assim, semelhantes, era predominante entre os imigrantes.

A migração e a definição dos trabalhadores migrantes e respectivas famílias como "étnicos" é considerada por Fenton (2003) um tópico importante para o estudo da etnicidade. "Muitas das populações identificadas como 'étnicas' no mundo contemporâneo são identificadas como tal porque são vistas por uma população indígena como imigrantes, quer sua migração seja recente quer seja bastante distante" (FENTON, 2003, p. 152).

Os principais grupos étnicos que vieram para a Quarta Colônia Impe- rial de Silveira Martins são os vênetos, oriundos da antiga República de Veneza, que dominou uma extensa região da península itálica, tendo durado mais de mil anos; os friulanos, provenientes da atual região do Friuli-Venezia-Giulia; os trentinos, oriundos da região do Trentino-Alto Adige, uma região que possui grande diversidade cultural, pois foi palco de várias disputas entre Austria e Itália; os lombardos provenientes da Lombardia, especialmente das cidades de Mantova e Bergamo, daí serem reconhecidos aqui como mantuanos; e os emilianos, a etnia menos numerosa, provindos da Emilia-Romagna. Todas essas etnias provieram de regiões com influência vêneta e falavam dialeto semelhante ao falado pelos venezianos.

\section{O papel da devoção religiosa na ne- gociação da identidade dos imigran- tes italianos}

A hipótese aqui considerada é de que a negociação da identidade dos grupos étnicos italianos em Silveira Martins deu-se por meio da devoção religiosa, e pode ser evidenciada mediante o patrimônio histórico (igrejas, capelas, capitéis, iconografia) dos movimentos religiosos e a introdução de devoções. A religião, nesse cenário, traduzia o universo simbólico das diversidades étnicas e culturais italianas, num processo de hegemonização, como se fossem circunstancialmente coesas, contudo heterogêneas. Dessa forma, este item disserta sobre o contexto da Igreja Católica no Brasil e no Rio Grande do Sul, no século XIX; a Igreja Católica na Região Central do Rio Grande do Sul, no final do século XIX; e a Igreja Católica nos primeiros anos de imigração italiana, na Colônia de Silveira Martins.

A Igreja Católica, no Brasil, organizou-se partindo do direito do $\mathrm{Pa}$ droado, que fora concedido pelo Papa ao rei português, com o objetivo de organizar a Igreja no Novo Mundo e, graças as novas atribuições do rei, a ex- 
pansão do catolicismo foi financiada. $\mathrm{O}$ rei era grão-mestre de três ordens militares e religiosas de Portugal: a Ordem de Cristo, considerada a mais importante e a herdeira dos Templários; a de São Tiago da Espada; e a de São Bento. O Estado português utilizava dois instrumentos para controlar a Igreja: a Mesa da Consciência e Ordens e o Conselho Ultramarino ${ }^{3}$. Entretanto, o Padroado Régio ainda foi o mais importante, pois, com sua predominância, dava pouco espaço à Cúria Romana, restringindo, assim, o poder da Igreja, especialmente o do Concílio de Trento, que somente foi introduzido no Brasil com a romanização ou ultramontanismo ${ }^{4}$, no final do século XIX (ABREU, 1999).

No Brasil, havia somente uma diocese, a de Salvador na Bahia, que foi fundada em 1551 e perdurou única até o final de 1676, quando foram criadas mais três dioceses: Pernambuco, Rio de Janeiro e São Luís do Maranhão. Na primeira metade do século XVIII, foram fundadas mais três: Pará, Mariana e São Paulo. Em razão de a Coroa Portuguesa somente interessar-se pela função episcopal e sacerdotal, à medida que estas estavam a seu serviço, as dioceses e paróquias ficaram vacantes por grandes períodos de tempo, e as visitas pastorais, recomendadas pelo Concílio de Trento, praticamente não se realizavam, em virtude das grandes distâncias e das dificuldades das viagens, que eram feitas em lombo de cavalo ou em redes carregadas pelos escravos, de modo que a vivência católica foi afetada pela estrutura eclesiástica. A igreja praticamente atendia somente o que chamamos de sacramentos obrigatórios, como batismo, casamento, confissão anual no tempo pascal, crisma e missa de defuntos. Os sacramentos eram considerados

${ }^{3}$ Mesa da Consciência e Ordens, que procedia às nomeações eclesiásticas e o Conselho Ultramarino, dava pareceres em questões de direito colonial.

${ }^{4}$ Ultramontanismo ou romanização, sinônimos: "movimento reformador das práticas católicas do século XIX [...] que buscava retomar as determinações do Concílio de Trento, sacralizar os locais de culto, moralizar o clero, reforçar a estrutura hierárquica da Igreja e diminuir o poder dos leigos organizados em irmandades". Cf. ABREU, Martha. O império do Divino: festas religiosas e cultura popular no Rio de Janeiro, 1830-1900. Rio de Janeiro: Nova Fronteira, 1999. p. 312 obrigatórios e aplicados à população em geral.

O clero secular era dividido em alto clero, que compreendia os bispos e outros dignitários pagos pelo Padroado Régio, e baixo clero, formado pelos párocos e capelães que viviam próximos ao povo, que com eles compartilhava suas privações.

Em consequência da parca literatura relacionada à vida do clero secular no Brasil, nos três primeiros séculos, ainda existem lacunas no que se refere ao celibato e ao seu envolvimento na política partidária, nas lutas do povo e na situação financeira. É preciso ressaltar a importância que a instituição eclesiástica teve na formação do Brasil colonial no que diz respeito ao quadro organizatório presente nos aldeamentos ou missões, aldeias e reduções. Essas não se limitaram apenas aos Sete Povos das Missões, na América Espanhola, mas também abrangem a Amazônia e numerosas áreas do litoral e interior, sendo consideradas por alguns autores como a experiência mais válida que partiu da igreja até os dias de hoje.

O patrimônio da Igreja Católica se manifestava por meio das ordens religiosas, em seus magníficos templos, mosteiros e conventos, e no luxo das igrejas barrocas, suntuosamente decoradas em ouro, fazendo parte também, desse patrimônio, um número impressionante de escravos. O chamado patrimônio dos santos ocupava espaço importante nas vilas, constituindo o centro dos povoamentos, onde, no seu entorno, tudo se desenvolvia.

A Igreja Católica estabeleceu-se no atual Rio Grande do Sul, quando chegaram os jesuítas espanhóis vindos do Paraguai para fundarem as Missões, compreendidas em duas fases: a primeira, das Reduções do Tape, no começo do século XVII; e, a segunda, dos Sete Povos das Missões, a partir de 1682, com a fundação de São Borja, e concluindo-se em 1707, com a fundação de Santo Ângelo. Ambas tinham a finalida- 
de de cristianizar os povos indígenas.

Ao longo do século XVIII, diversos luso-brasileiros protagonizaram a incorporação do atual território sul-riograndense aos domínios da América Portuguesa. Estes conquistadores construíram a Capitania Geral de Rio Grande, ligada ao Bispado do Rio de Janeiro, o qual enviava os padres para os povoados de Viamão, Rio Grande, Santo Antonio da Patrulha, Nossa Senhora Madre Mãe de Deus de Porto Alegre e Rio Pardo, para que cuidassem dos católicos da Capitania. Dessa maneira, os sul-rio-grandenses, desde o século XVIII até meados do século XIX, não eram atendidos por um bispo próprio, já que a Igreja Católica da Capitania e, posteriormente, Província de São Pedro, não era assistida por um sacerdote próprio.

A Igreja Católica no Rio Grande do Sul, como em todo o império, era reduzida a um insignificante número de paróquias, igrejas e padres carentes de paramentos e com uma evidente falta de recursos, fato que preocupava os membros da hierarquia eclesiástica.

Em maio 1847, o Senado do Império aprovou a criação do Bispado da Província de São Pedro do Rio Grande do Sul, sendo assim encaminhado à Roma um pedido de criação e instalação da nova diocese, que se deu em sete de maio de 1848, pela Bula Ad Oves Dominicas rite Pascendas, do Beato Pio IX. O primeiro Bispo do Rio Grande do Sul foi Dom Feliciano José Rodrigues de Araújo Prates, nomeado pelo Beato Pio IX, em 26 de setembro de 1852, para assumir a Diocese criada em 1848, com nome de São Pedro do Rio Grande do Sul.

Dom Feliciano foi sucedido pelo Bispo D. Sebastião Laranjeiras (18201888), o qual se queixava que os padres, que eram formados dentro da filosofia do catolicismo liberal, viviam entregues aos prazeres materiais e terrenos, e o povo católico deveria manter-se distante de doutrinas liberais, maçônicas, racionalistas, materialistas, protestantes e comunistas. As ordens vindas da Cúria
Romana eram claras e combatiam toda e qualquer doutrina de caráter liberal e quaisquer coisas com tal proveniência, consideradas erradas e perigosas para a Igreja, e que, naturalmente, enfraqueciam a doutrina estabelecida pelo Concílio de Trento e pela hierarquia papal, contrariando o modelo ultramontano que a igreja tentava implantar.

O processo histórico de fundação de Santa Maria está vinculado a esses acontecimentos. A cidade teve a sua origem em um acampamento militar nos limites estabelecidos pelo tratado de Santo Ildefonso, na região denominada de depressão central, passagem natural entre a área de domínio português e a região das missões recém-conquistada da Espanha. Em 1814, ainda sobre a circunscrição de Cachoeira do Sul, recebeu o Estatuto de Capela Curada. Em 1837, passando a ser denominada Freguesia de Santa Maria da Boca do Monte e, logo a seguir, Paróquia de Nossa Senhora da Conceição. Em 1857, passou à condição de vila e, em 1858, a município.

A distância do bispado de Porto Alegre e os parcos recursos da igreja para a manutenção dos templos contribuiram para que, em 1884, a Câmara Municipal de Vereadores declarasse a interdição e demolição do templo católico, que oferecia perigo aos fiéis. Logo a seguir, foi providenciada a construção de outra capela, denominada Capela do Império do Divino Espírito Santo, que, naturalmente, não agradou ao padre José Marcelino de Souza Bittencourt. Esse foi um período de grandes conflitos, pois havia na cidade três lojas maçônicas, uma efervescência do partido liberal e a ascensão da Igreja Luterana, trazida pelos imigrantes alemães, o que ameaçava a hegemonia da Igreja Católica. A Igreja avaliava a situação como negativa, pois era pouco frequentada, quase não se praticavam os sacramentos, e não havia missa diária. Os problemas eram tantos, que a paróquia foi interditada por mais de três meses pelo 
bispo, de 17 de novembro de 1895 a 3 de março de 1896. É com esse sentimento de derrota e precariedade que a igreja mergulha no período republicano, momento em que ocorreu o rompimento entre a Igreja e o Estado. Santa Maria, nesse contexto, foi o palco para a implantação do ultramontanismo, sendo os padres palotinos os convidados a iniciarem a sua "guerra santa".

Os imigrantes italianos chegaram à região a partir de 1876, ocupando as terras da colônia criada oficialmente pelo Decreto Imperial de Dom Pedro II em 1875, denominada Quarta Colônia Imperial de Imigração Italiana do Rio Grande do Sul. O local, chamado pelos imigrantes como Baracon de Val de Buia, foi o palco onde os recém-chegados "italianos" começaram a atuar em terras brasileiras.

No grupo dos emigrados, havia gente de regiões como Vêneto, FriuliVenezia-Giulia, Trentino, Lombardia e Emilia-Romagna, todos de línguas e culturas diferentes. Para Zanini (2006, p. 137), "o que os tornava iguais, sem dúvida, era o fato de serem católicos e se perceberem como sujeitos que haviam compartilhado a mesma experiência social de ruptura - eram emigrados".

No Baracon, os recém-chegados "italianos" estavam sujeitos a todo o tipo de privações: as instalações eram péssimas, não havia camas, local para banho, cozinha, nada que fizesse alusão a um ambiente habitável para um ser humano. As famílias não tinham privacidade e estavam sujeitas, também, às intempéries.

Os emigrados já chegavam física e emocionalmente debilitados, em razão da longa travessia, do confinamento e, ainda, das perdas de familiares ocorridas na viagem. Ao chegarem, permaneciam pessimamente instalados por vários meses, até receberem suas colônias de terra e se transformarem em colonos.

Em razão das condições precárias, muitos adoeciam e morriam sem assistência médica, o que até era aceito, mas não sem assistência espiritual. Para o imigrante, a fé cristã era fundamental e, especialmente nesse momento de grande insegurança, a fé foi o suporte para enfrentar a conquista da nova vida. Podia privar-se de muitas coisas, mas jamais da presença daquele que representa o Filho de Deus aqui na terra. Surgiram, nessa conjuntura, os preti $d i$ scapoera, padres leigos, que em geral eram pessoas mais idosas, religiosas, de cultura e moral consideráveis.

A primeira assistência religiosa aos emigrados foi dada pelo Cônego José Marcelino de Souza Bittencourt, pároco em Santa Maria. Afirma Barea (1995, p. 66) que

[...] em 19 de maio de 1878, o mesmo sacerdote se achava de novo em meio aos imigrantes na atual sede de Silveira Martins, onde, sob uma choupana, coberta com lençóis e ramos de árvores, celebrou a primeira missa com grande satisfação daqueles bons camponeses, que saudaram esse ato religioso com numerosos disparos de mosquete (BAREA, 1995, p. 66).

Descontentes com a falta de sacerdotes na colônia, que já se expandira para o vale, depois de solicitarem as devidas providências ao Bispo local, que não foram atendidas, um grupo de colonos, liderados por Paolo Bortoluzzi, morador de Vale Vêneto, organizou-se e decidiu importar um padre. Optaram por um italiano, para facilitar a comunicação, já que os emigrados falavam dialetos próximos ao italiano clássico. Contrataram, então, um procurador, chamado Antonio Vernier e patrocinaram sua ida à Itália. Depois de permanecer três anos na península e fazer muitos contatos, o procurador encontrou dois voluntários que aceitaram vir para a Quarta Colônia. Os candidatos chamavam-se Vittore Arnolfi e Antônio Sório, ambos da região do Vêneto, o primeiro 
oriundo de Feltre e o segundo de Verona. Chegaram à cidade de Porto Alegre em 1881. Com poucos recursos financeiros, hospedaram-se em um hotel e aguardaram a recepção dos colonos. Foi uma espera vã, pois não havia ninguém para recepcioná-los.

A chegada dos padres a Vale Vêneto despertou curiosidade e constrangimento aos moradores de Silveira Martins, pois, com a presença dos sacerdotes na localidade, a gestão do cemitério, registros de batismo, óbito e casamento passariam todos para Vale Vêneto.

Próspero Pippi, liderando um grupo de silveirenses, marcou uma audiência com o Bispo Dom Sebastião Laranjeiras, quando foi reivindicada a permanência dos padres em Silveira Martins. O Bispo decidiu por bem que Arnolfi iria para Silveira Martins e Sório para Vale Vêneto.

Em 25 de abril de 1884, com o falecimento do padre Vittore Arnolfi, o padre Antônio Sório passou então a ser o capelão. Sório colocou a $1^{\mathrm{a}}$ pedra da nova igreja, benta pelo pároco de Santa Maria, em nove de janeiro de 1890, começando, assim, a grande obra da Igreja Matriz Santo Antonio de Pádua, santo padroeiro do município.

Com a morte de Sório, em 1890, o padre palotino alemão Frederico Schwinn assumiu a paróquia e finalizou a obra da igreja, construindo a torre cilíndrica em estilo bizantino-românico e, a partir de então, começou a construção das capelas nas diversas linhas do povoado.

Segundo Zanini (2006b, p. 137),

[...] a religião foi um dos elementos mais importantes no processo de enraizamento do emigrado em terras brasileiras. Se os sacerdotes tiveram sua parcela de responsabilidade na emigração tiveram-na também no processo de adaptação desses sujeitos em um mundo estrangeiro e na legitimação das representações advindas desse encontro (ZANINI, 2006b, p. 137).

A construção das capelas de di- ferentes devoções nas diversas linhas, as celebrações religiosas e os festejos relativos aos santos padroeiros de cada local foram maneiras que os imigrantes encontraram para negociarem a identidade regional e legitimarem-se como grupo étnico junto às populações e etnias já estabelecidas na região. Ainda conforme Zanini (2006b, p. 138), "a vivência religiosa construiu um território simbólico de segurança e estabilidade, visível nos capitéis, capelas e igrejas e nas imagens dos padroeiros".

A repetição de habitus, como o repicar dos sinos, trouxe familiaridade aos emigrados, lembrando o som ouvido nos seus paesi de origem, que haviam ficado na Europa, ao mesmo tempo em que se constituía em um elo em comum com a religiosidade dos grupos aqui encontrados. Partindo desse traço comum, a religiosidade foi negociada à identidade regional. Atestados dessa constante negociação podem ser encontrados no patrimônio histórico religioso da região da Quarta Colônia de Imigração Italiana.

\section{Considerações finais}

Nas obras pesquisadas que fazem referência às práticas religiosas no Brasil desde a implementação da Igreja Católica no novo mundo (AZZI, 1990; BAREA, 1995; BEOZZO, 1987; BIASOLI, 2008; COSTA, 1986; DE BONI, 1987,1990, 1996; RUBERT, 1998; VÉSCIO, 2001), é comum encontrarmos palavras como padroado, regalismo, liberalismo, irmandades, maçonaria, confrarias, bulas, positivismo, iluminismo, jesuitismo, entre outras, mas o que mais nos chama a atenção, considerando oportuno relacionar ao momento da chegado dos imigrantes italianos, é o ultamontanismo.

Quando os imigrantes italianos chegaram ao Quarto Distrito de Santa Maria, a Igreja Católica local vivia seu pior momento, pois a maçonaria, o movimento liberal e a ascensão da Igreja 
Luterana ameaçavam a sua hegemonia. Os imigrantes italianos exigiam a presença de uma igreja forte, com os valores e determinações do Concílio de Trento. Apesar da presença de carbonários, anarquistas, garibaldinos e maçons, a grande maioria dos imigrantes tinha presente os valores ultramontanos que a Igreja havia começado a implantar.

Os diferentes grupos étnicos, por meio de relações de solidariedade entre as etnias e aceitação ou de conflitos com o status quo religioso já estabelecido foram, ao longo de décadas, negociando a sua identidade.

Os imigrantes negociaram com as etnias já estabelecidas, dialogaram com várias culturas, aprenderam a conviver com as outras etnias italianas e entre os "italianos" e com as etnias já enraizadas em solo brasileiro. Tanto a negociação entre as etnias italianas, quase uma "negociação endógena", como a negociação com as etnias já estabelecidas, que podemos chamar de "negociação de identidade exógena", deu-se por meio da religiosidade.

Entre as etnias italianas, a escolha do próprio santo padroeiro de cada linha significava disputa de poder entre etnias ou o predomínio de uma etnia ou família proveniente de uma etnia italiana. Cabe lembrarmos que a unificação tardia da Itália (1875) fez com que as etnias que vieram para o Brasil apresentassem marcadas diferenças culturais.

Para as etnias estabelecidas anteriormente na região, este mosaico étnico de vênetos, lombardos, friulanos, trentinos e emilianos, era visualizado apenas como "os italianos", "os imigrantes italianos", o que lhes atribuía uma unidade identitária que não existia de fato. A Igreja Católica, já estabelecida, procurava inculcar nos "imigrantes" a brasilidade: o tornar-se brasileiro, inclusive pela atuação política como brasileiro, o que foi mais explícito durante o Estado Novo.

A atuação da Igreja Católica, já estabelecida, representava as estratégias do poder já instituído para tornar brasileiros os imigrantes. Entretanto, o cotidiano trazia devoções e práticas religiosas de suas regiões de origem e, no espaço das capelas, oratórios, lares e festas dos padroeiros, foi sendo negociada uma devoção pragmática que perguntava: Este santo serve para o quê? Em que vai me ajudar? É um santo forte?

Dessa negociação, surgiram linhas com vários padroeiros, introduzidos em épocas diferentes, como resultado de acordos entre os habitantes das localidades, de acordos entre as comunidades de Silveira Martins ou, ainda, entre elas, as diferentes localidades e a igreja já estabelecida.

Podemos sintetizar que o resultado dessa negociação identitária foi uma maior convivialidade entre as peças desse mosaico formado pelas etnias italianas, embora não chegassem, nem de perto, a configurar o bloco monolítico, como eram vistos pelas etnias já estabelecidas.

\section{Referências}

ABREU, Martha. O império do divino: festas religiosas e cultura popular no Rio de Janeiro, 1830-1900. Rio de Janeiro: Nova Fronteira, 1999.

AZZI, Riolando. Fé e italianidade: a atuação dos Escalabrinianos e dos Salesianos junto aos imigrantes. In: DE BONI, Luis Alberto. A presença italiana no Brasil. v. II. Porto Alegre: EST, 1990. p. 63-80.

BARTH, Frederik. Los grupos étnicos y sus fronteras. Mexico: Fondo de Cultura Económica, 1976.

BAREA, Dom José. A vida espiritual nas colônias italianas do estado do Rio Grande do Sul. Porto Alegre: Est, 1995. 
BEOZZO, José Oscar. O clero italiano no Brasil. In: DE BONI, Luis Alberto. A presença italiana no Brasil. v. I. Porto Alegre: EST, 1987.

BIASOLI, Vitor Otávio Fernandes. O catolicismo ultramontano e a conquista de Santa Maria da Boca do Monte (RS1870-1920). In: MILDER, Saul Eduardo S. (Org.). Recortes da história brasileira. Porto Alegre: Martins Livreiro, 2008. p. 83-100.

BOURDIEU, Pierre. A economia das trocas simbólicas. 2. ed. São Paulo: Perspectiva, 1998.

COSTA, Rovílio et al. Imigração italiana no Rio Grande do Sul. Porto Alegre: EST; Caxias do Sul: EDUCS, 1986.

DE BONI, Luis Alberto. A presença italiana no Brasil. v. I. Porto Alegre: EST, 1987.

DE BONI, Luis Alberto. A presença italiana no Brasil. v. II. Porto Alegre: EST, 1990.

DE BONI, Luis Alberto. A presença italiana no Brasil. v. III. Porto Alegre: EST, 1996.

FENTON, Steve. Etnicidade. Lisboa: Instituto Piaget, 2003.

LESSER, Jeffrey. A negociação da identidade nacional. Imigrantes, minoria e a luta pela etnicidade no Brasil. São Paulo: UNESP, 2001.

OLIVEIRA, Roberto Cardoso de. Identidade, etnia e estrutura social. São Paulo: Pioneira, 1976.
ORO, Ari Pedro. "Mi son talian": considerações sobre a identidade étnica dos descendentes de italianos do Rio Grande do Sul. DE BONI, Luis Alberto. A presença italiana no Brasil. v. III. Porto Alegre: EST, 1996.

POUTIGNAT, P.; STREIFF-FENART, J. Teorias da etnicidade. São Paulo: UNESP, 1998.

RUBERT, Arlindo. História de igreja no Rio Grande do Sul: época imperial (1822-1889). Porto Alegre: EDIPUCRS, 1998.

VÉSCIO, Luiz Eugênio. O crime do Padre Sório: Maçonaria e Igreja Católica no Rio Grande do Sul 1893-1928. Santa Maria: UFSM; Porto Alegre: UFRGS, 2001.

ZANINI, Maria Catarina Chitolina. Italianidade no Brasil meridional: a construção da identidade étnica na região de Santa Maria RS. Santa Maria: UFSM, 2006a.

ZANINI, Maria Catarina Chitolina et al. A etnografia em questão. Sociais e Humanas, Santa Maria, v. 19, n. 2, p. 135-43, jul./dez., 2006 b. 